\title{
Voting, Wealth Heterogeneity, AND ENDOGENOUS LABOR SUPPLY*
}

\author{
Chetan Ghate \\ Planning Unit, Indian Statistical Institute, New Delhi \\ FinAL Version: June 6, 2007
}

Date of Submission: September 15, 2006.

\footnotetext{
*This paper has benefitted from comments at the theory workshop at the University of New South Wales, the 5th Journées $d^{\prime}$ économique publique Louis - André Gérard - Varet - June 2006, the 2006 South and South East Asia Econometric Society Meetings, Chennai, and the February 2007 JNU - Delhi Conference "Institutions: Efficiency, Growth and Equity." I thank Debajyoti Chakrabarty, Lutz Hendricks, and Patrick Pintus for excellent comments. I also thank two anonymous referees, and the Editor, Alfons J. Weichenrieder, for helpful suggestions. An earlier working paper version was entitled 'Transitional Dynamics in a Growth Model with Distributive Politics'. The usual disclaimer applies.
} 


\begin{abstract}
We examine the link between voting outcomes, wealth heterogeneity, and endogenous labor leisure choice in the majority voting - endogenous growth frameworks of Alesina and Rodrik (1994) and Das and Ghate (2004). We augment these frameworks to incorporate leisure dependent utility and allow households to vote over factor specific income taxes. When agents vote over factor specific taxes, we show that the asymptotic convergence of factor holdings does not imply unanimity over the growth maximizing tax policy in the steady state. Unanimity over growth maximizing policies holds only when agents vote over a general income tax, and when agents vote over factor specific taxes but labor is exogenous.
\end{abstract}

KEYwords: Factor Income Taxation, Endogenous Distribution, Median Voter Theorem, Heterogenous Agents, Endogenous Labor Supply.

Journal of Economic Literature Classification Number: P16: Political Economy of Capitalism; E62: Fiscal Policy; O40 Economic Growth. 


\section{Introduction}

We examine the implications of an endogenous labor leisure choice on the equilibrium tax rate in a heterogenous agent Barro (1990) type endogenous growth framework. We allow for voting over factor specific income taxes and examine the links between voting outcomes and wealth heterogeneity when labor is endogenous. The theoretical model augments the frameworks of Das and Ghate (2004) - henceforth DG - and Alesina and Rodrik (1994)- henceforth AR. We extend these frameworks by incorporating leisure dependent utility and allowing for voting over factor income taxes. Like DG and $\mathrm{AR}$, the equilibrium tax rate is determined under majority voting, and redistribution occurs through the tax rate. Income inequality is defined in terms of the functional distribution of income. Majority voting determines the extent of redistribution and thus a relationship between inequality and growth in a simple way.

Our analysis makes two contributions. First, we characterize the dynamics of wealth inequality and the steady state distribution of factor holdings. We show that the steady state dynamics of wealth inequality are unaffected by the underlying factor specific tax system: there is complete convergence of factor holdings in the steady state as in Stiglitz (1969). Our second contribution constitutes the main result of the paper: while there is unanimity over the tax rate in the steady state, convergence in factor holdings doesn't imply unanimity over the growth maximizing tax policy. In the steady state, the equilibrium capital income tax rate is less than the growth maximizing tax rate, while the equilibrium labor income tax rate is greater than the growth maximizing tax rate. Both outcomes lead to lower steady state growth. 
Our general result is to show that unanimity over the growth maximizing tax rate depends crucially on how labor supply varies with respect to individual factor taxes. We identify the intuition behind these results.

Our research is motivated by a large body of literature that analyzes redistributive policies and economic growth in an endogenous growth framework. ${ }^{1}$ Our framework is similar to the majority voting - endogenous growth models developed in Alesina and Rodrik (1994) and Das and Ghate (2004). ${ }^{2}$ However, neither of these models endogenizes labor supply. We show that endogenizing labor supply through leisure dependent utility has significant implications for the unanimity results obtained in DG, Ghate (2005), and AR. ${ }^{3}$

Endogenizing labor supply has an additional motivation that we think is important: to 'fully' endogenize the dynamics of wealth inequality in the frameworks of DG, Ghate (2005), and AR. In AR the distribution of wealth remains constant and

\footnotetext{
${ }^{1}$ There is ample evidence supporting the empirical validity of an AK-type endogenous growth model. For instance, Li (2002) conducts a number of time series and panel-data tests employing more extensive data sets and a broader definition of investment. Li (2002) finds that both the time series as well as panel evidence for a large number of OECD countries accords with the implications of the AK model. Similarly, using annual data for 98 countries from 1960-1998, Bond, Leblebicioglu, and Schiantarelli (2004) find that an increase in the share of investment predicts a higher growth rate of output per worker, both in the short run as well as the steady state. This evidence is consistent with the main implications of AK type endogenous growth models.

${ }^{2}$ Ghate (2005) is also similar to these papers although Ghate (2005) extends the unanimity results in DG to the case of a general income tax. Ghate (2005) shows that when voting over a general income tax, unanimity occurs in both the short run and long run. In DG, unanimity holds only in the long run.

${ }^{3}$ Bertola (1993) also analyzes the growth and distributional effects of fiscal policy in the context of a simple endogenous growth model with externalities. While Bertola's setup also leads to a monotonic positive relation between capital subsidy rates and growth, in the current framework the growth rate is 'hump-shaped' with respect to factor specific taxes, as in AR and DG.
} 
is pinned down by the initial distribution of capital. While this allows AR to explain the growth effects of different after tax wealth distributions, they cannot account for how growth influences the distribution of wealth as this always remains constant. DG endogenize the dynamics of wealth inequality in AR, although in DG the steady state distribution of factor composition ratios is pinned down by the exogenous distribution of skill. Hence, in both DG and Ghate (2005), the equilibrium factor holdings remains exogenous. In the model proposed here, agents are different only in terms of their capital holdings (not skill) and value leisure. This 'fully' endogenizes the dynamics of wealth inequality both in and outside the steady state. The model is therefore more general.

Incorporating leisure dependent utility is consistent with a large literature that studies the growth effects of endogenous labor supply (see de Hek $(1998,2006)$; Eriksson (1996); Ladron-de-Guevara et al. (1997, 1999); Ortigueira (1998, 2000); and Turnovsky $(1999,2000))$. An important feature of these models is that they employ an infinite horizon representative agent framework. One of the focuses of this literature is to study how leisure dependent utility induces multiple equilibria. ${ }^{4}$ In

\footnotetext{
${ }^{4}$ For instance, de Hek (1998) constructs a one sector aggregative growth model where both consumption and leisure enter as arguments into the utility function. de Hek (1998) shows that either multiple steady states or non-monotone (cyclical) behavior obtain. Similarly, de Hek (2006) constructs a model similar to Rebelo (1991) augmented with an endogenous labor leisure choice. de Hek (2006) shows that these features lead to multiple balanced growth paths. Ladron-de-Guevara et al. (1999) presents and endogenous growth model with unqualified leisure in the utility function [i.e, leisure not adjusted by the stock of human capital]. Orteguierra (2000) also examines the dynamic implications of qualified leisure. These authors also show that multiple growth paths may arise. Finally, Ladron-de-Guevara et al. (1997) show that there could be multiple balanced growth paths in an endogenous growth model with human capital if leisure is endogenously determined.
} 
contrast, we show that multiple equilibria do not arise when leisure dependent utility is incorporated into the frameworks of DG and AR. This is because the marginal benefit and marginal cost schedules of higher factor specific taxes are monotonically decreasing and increasing, respectively. This guarantees a unique equilibrium tax rate.

Another focus of the literature on the growth effects of endogenous labor supply - while maintaining the representative agent framework - is to consider the consequences of endogenizing labor supply for fiscal policy. For instance, Orteguierra (1998) studies the impact of labor and capital income taxation on the transitional dynamics to the balanced growth path using a two sector framework. Orteguierra (1998) shows that distortionary taxes may exert a non-negligible influence on equilibrium behavior both along the transitional dynamics as well as the balanced growth path. Turnovsky (2000) shows that endogenizing labor supply leads to fundamental changes in the equilibrium tax structure of the AK growth model. Turnovsky (1999) examines the equilibrium structure of a small open economy and shows that the introduction of an elastic labor supply leads to a less (rather than more) potent role to distortionary taxes in terms of influencing growth. ${ }^{5}$ In our model, agents are assumed to be heterogenous with respect to wealth holdings, single period lived, and have a one sided bequest motive. Households enjoy utility from leisure and care about the future capital stock. They inherit bequests and pay taxes on their inherited income.

\footnotetext{
${ }^{5}$ Eriksson (1996) shows that unlike the standard optimal growth model, preferences over consumption and leisure can affect the steady state growth rate (although not the rate of time preference). However, Eriksson (1996) does not analyze fiscal policy.
} 
Because of the finite lifetime assumption plus the diminishing marginal utility from bequests, this introduces transitional dynamics. ${ }^{6}$ Further, the assumed heterogeneity generates a mapping between household specific wealth holdings and their preferred tax rates. Convergence to the representative agent's wealth holding occurs in the steady state - irrespective of the initial distribution of wealth - as the factor holding ratios of all agents converge to that of the representative agent.

\section{The Model with Capital Income Taxes}

We now formalize the model. We first allow for voting over the capital income tax rate. In the next section, we allow for voting over the labor income tax rate, and finally, a general income tax. In each case we analyze the dynamics of wealth inequality, and solve out the equilibrium tax rate under majority voting and compare it to the growth maximizing tax rate. We solve the household's problem with labor supplied endogenously.

The population, or number of households, $N$, is given. Each household is differentiated on the basis of its capital holdings, $K_{h}$, whose distribution is assumed to be continuous on a finite support, $R_{+}$. The distribution of $K_{h}$ is skewed to the right. This implies that the median household's capital holdings is less than the mean household's. The aggregate stock of capital is given by $K=\sum_{1}^{N} K_{h}$. Capital is the only accumulable factor in the model. ${ }^{7}$

\footnotetext{
${ }^{6}$ In contrast, in the Turnovsky $(1999,2000)$ style AK framework, the economy will always lie on its balanced growth path.

${ }^{7}$ The current setup differs with respect to DG and Ghate (2005) as in these papers agents are heterogenous with respect to skill, not capital holdings.
} 
A single good is produced in the economy according to a Cobb-Douglas production technology, given by

$$
Y_{t}=K_{t}^{a}\left(G_{t} H_{t}\right)^{1-a}
$$

where $Y_{t}$ is aggregate output at time period $t, K_{t}$ denotes the aggregate capital stock in the economy, $H_{t}$ is the aggregate labor supply in each period, and $G_{t}$ is a public infrastructure input which is the source of labor augmentation. We assume that $G$ is a pure public good as in Barro (1990). ${ }^{8}$ Following the endogenous growth literature, we interpret $K$ as both physical as well as human capital. Hence $a \in[0,1]$ is the private return to physical capital as well as human capital. We require the regularity condition, $a>\frac{1}{2}$, to ensure that the return to capital is positive in equilibrium. ${ }^{9}$

We assume that the public infrastructure input, $G$, is financed by a specific tax, $\tau_{k} \in[0,1]$, on capital income in each period. This specification is more empirically plausible, and departs from both $\mathrm{AR}$ and DG, who assume that infrastructure is financed by a tax on the capital stock, or wealth. The government budget constraint is balanced in each period, and given by, $G_{t}=\tau_{k t} r_{t} K_{t}$, where, $r_{t}$ is the competitive rate of return to capital. Given (1), the rental rate to capital, $r_{t}$, and the wage rate, $w_{t}$, are given by: $r_{t}=\phi\left(\tau_{k t}\right) H_{t}^{\frac{1-a}{a}}$, and, $w_{t}=\xi\left(\tau_{k t}\right) H_{t}^{\frac{1-2 a}{a}} K_{t}$, respectively, where,

\footnotetext{
${ }^{8}$ See Barro $(1995$, p. 153) for a discussion on the definition of $G$. We assume a Cobb-Douglas production structure primarily for analytical tractability. However, recent empirical evidence casts doubt on the Cobb - Douglas specification (see Bentolila and Saint-Paul (2003) and Duffy and Papageorgiu (2000)).

${ }^{9}$ With a narrower interpretation of $K$ as physical capital, it would be empirically implausible to assume that $a>\frac{1}{2}$, but it is not so when capital is interpreted more broadly as we do here. Further, according to Barro and Sala-i-Martin (1995, p. 38), even a value of $\alpha=.75$ is quite reasonable. See DG for details.
} 
$\phi\left(\tau_{k t}\right)=a^{\frac{1}{a}} \tau_{k t}^{\frac{1-a}{a}}$, and $\xi\left(\tau_{k t}\right)=(1-a) a^{\frac{1-a}{a}} \tau_{k t}^{\frac{1-a}{a}}$. This allows us to write the after tax rental - wage ratio as

$$
\frac{r_{t}}{w_{t}}=\frac{a H_{t}}{(1-a) K_{t}}
$$

Without any loss of generality, we assume that capital depreciates fully in each period.

Following Aghion and Bolton (1997), agents are assumed to live for a single period. In each period, household's are also endowed with a single unit of time which they allocate optimally between labor and leisure. The tax rate is known before households make their consumption, bequest, and labor supply decisions. Households decide their labor supply choices at the beginning of each period after which production occurs. Once production occurs, households make their consumption and bequest decisions, and then die. Hence, at time $t$, the $h^{t h}$ household derives utility over consumption, $C_{h t}$, a bequest $K_{h t+1}$, and leisure, $1-H_{h t}$, where $H_{h t}$ is the amount of labor supplied by the $h^{t h}$ household in time period $t$. The utility function $U: \mathbb{R}_{+}^{3} \rightarrow R_{+}$satisfies the standard properties, and is assumed to be Cobb-Douglas for tractability.

The household's problem is to maximize

$$
\operatorname{Max}_{C_{h t}, K_{h t+1}, H_{h t}} C_{h t}^{\alpha} K_{h t+1}^{\beta}\left(1-H_{h t}\right)^{1-\alpha-\beta}
$$

subject to

$$
C_{h t}+K_{h t+1} \leq w_{t} H_{h t}+r_{t}\left(1-\tau_{k t}\right) K_{h t}
$$

where $\alpha \in(0,1), \beta \in(0,1)$, and $\alpha+\beta \leq 1^{10}$

\footnotetext{
${ }^{10} \mathrm{~A}$ more general approach would be to allow factor specific and flat rate taxes to represent benchmark cases of a more continuous tax system: i.e., write equation (4) as $C_{h t}+K_{h t+1} \leq(1-$ $\left.\tau_{w t}\right) w_{t} H_{h t}+r_{t}\left(1-\tau_{k t}\right) K_{h t}$, where $\tau_{w t} \in[0,1]$ denotes the tax on labor income, while, $\tau_{k t} \in[0,1]$
} 
The optimization exercise implies the following household decision rules,

$$
\begin{gathered}
C_{h t}=\frac{\alpha}{\beta} K_{h t+1}, \\
K_{h t+1}=\frac{\beta}{\alpha+\beta}\left\{w_{t} H_{h t}+r_{t}\left(1-\tau_{k t}\right) K_{h t}\right\}
\end{gathered}
$$

and

$$
H_{h t}=(\alpha+\beta)-(1-\alpha-\beta)\left[\frac{r_{t}\left(1-\tau_{k t}\right)}{w_{t}}\right] K_{h t}
$$

Equation (5) governs optimal consumption. Equation (6) is the household capital accumulation equation. What is new in relation to DG is equation (7) which is the household labor supply equation. This is increasing in the tax rate on capital income. Intuitively, a higher tax rate raises infrastructure, $G$, which increases the rewards from working. This induces households to supply more labor. Noting that $\sum_{1}^{N} H_{h t}=H_{t}$, using (2), and re-arranging equation (7) leads to an expression for aggregate labor supply determined endogenously as a function of the tax rate,

$$
H_{t}=H\left(\tau_{k t}\right)=\frac{N(\alpha+\beta)(1-a)}{(1-a)+a(1-\alpha-\beta)\left(1-\tau_{k t}\right)} .
$$

Let $\delta\left(\tau_{k t}\right)=(1-a)+a(1-\alpha-\beta)\left(1-\tau_{k t}\right)$. It is easy to verify that $H^{\prime}\left(\tau_{k t}\right)>0, \forall \tau_{k t} \in$ $[0,1]$. Similarly, the aggregate capital accumulation equation is given by:

$$
K_{t+1}=\frac{\beta}{\alpha+\beta}\left\{\xi\left(\tau_{k t}\right) H_{t}^{\frac{1-a}{a}}+\phi\left(\tau_{k t}\right)\left(1-\tau_{k t}\right) H_{t}^{\frac{1-a}{a}}\right\} K_{t} .
$$

denotes the tax rate on capital income. This way of formulating the consumer budget constraint would allow all three cases: $\tau_{w t}=0, \tau_{k t}=0$, and a flat income tax rate, $\tau_{w t}=\tau_{k t}=\tau_{t}$. However, it is well known that the median voter theorem holds only if voting occurs over a single policy, and second, the model below cannot be solved analytically under a more complex tax system in which optimal growth is implemented as the outcome of a voting process with differentiated non-zero tax rates on both factors of production. 
Equations (8) and (9) denote the aggregate decision rules for labor and capital, respectively.

Next, as in DG and Ghate (2005), we define the economy growth rate as $g_{t+1}=$ $\frac{K_{t+1}}{K_{t}}$, which is given by, ${ }^{11}$

$$
g_{t+1}=\text { constant } \cdot\left\{(1-a)+a\left(1-\tau_{k t}\right)\right\}\left(\tau_{k t} H_{t}\right)^{\frac{1-a}{a}},
$$

where the term constant $=\frac{(\alpha+\beta)}{\beta} a^{\frac{1-a}{a}}$. Equations (10) and (8) determine the long run endogenous growth rate of the economy. The growth-tax curve takes the well known inverse U-shape form, as in Barro (1990) which leads to a unique growth maximizing tax rate. We denote this as $\tau_{e}^{g}$. It can be shown that the exogenous growth maximizing tax rate, $\tau_{x}^{g}$, is given by $\tau_{x k}^{g}=\frac{1-a}{a}$, where $\tau_{x k}^{g}$ denotes the growth maximizing tax rate when $\alpha+\beta=1 .{ }^{12}$ This allows us to provide a sufficient condition for the existence of a unique growth maximizing tax rate under endogenous labor-leisure $(\alpha+\beta<1)$ and compare it with the growth maximizing tax rate under exogenous labor-leisure $(\alpha+\beta=1)$.

Proposition 1 Suppose $\alpha+\beta<1$. There exists a unique growth maximizing tax rate under endogenous labor leisure, $\tau_{e k}^{g}$, which is greater than the growth maximizing

\footnotetext{
${ }^{11}$ More accurately, $g_{t+1}$, refers to the growth factor or gross growth rate. Since our results would not change if we used the growth rate, $\frac{K_{t+1}}{K_{t}}-1$, we use these terms interchangeably. To obtain an expression for $g_{t+1}$, we substitute out the expression for $H_{h t}$ (using (7) in (6)), aggregate across households, and simplify. This yields: $K_{t+1}=\beta\left\{N w_{t}+r_{t}\left(1-\tau_{k t}\right) K_{t}\right\}$. From equation (2), the wage rate can be expressed as, $w_{t}=\frac{(1-a) K_{t} r_{t}}{a H_{t}}$. Using this expression for $w_{t}$, the expression for the rental rate, and substituting out the expression for $H_{t}$ from (8) into the above expression for $K_{t+1}$ leads to equation (10)

${ }^{12}$ To see this, note that by Euler's theorem, $Y_{t}=\frac{\partial Y}{\partial K} K_{t}+\frac{\partial Y}{\partial H} H_{t}=r_{t} K_{t}+w_{t}$ where we normalize $H$ to 1 . This implies $w_{t}+r_{t}\left(1-\tau_{k t}\right) K_{t}=w_{t}+r_{t} K_{t}-\tau_{k t} r_{t} K_{t}=Y_{t}-r_{t} K_{t}$. Substituting out for $Y_{t}$ and differentiating with respect to the tax rate yields the desired result.
} 
rate under exogenous labor leisure,i.e.,

$$
\tau_{e k}^{g}>\tau_{x k}^{g}=\frac{1-a}{a} .
$$

if and only if $2 a-1>a(1-\alpha-\beta)(1-a)$.

Proof. See Appendix.

As shown in the appendix, the growth maximizing tax rate under $\alpha+\beta<1$, $\tau_{e k}^{g}$, is obtained from differentiating equation (10) with respect to $\tau_{k t}$. After manipulating this expression, this leads to a constant growth maximizing tax rate, which is determined by:

$$
\underbrace{(1-a)\left\{a \tau_{e k}^{g}-(1-a)\right\}}_{M C}=\underbrace{(1-\alpha-\beta) a\left[(1-a)\left(1-a \tau_{e k}^{g}\right)-a(1-\tau) a \tau_{e k}^{g}\right]}_{M B} .
$$

Figure 1 plots the marginal cost and benefit schedules corresponding to the growth maximizing tax rate under $\alpha+\beta<1$ and $\alpha+\beta=1$ based on Equation (12). $\tau_{e k}^{g}$ is determined by the intersection of these two schedules. As $\alpha+\beta \rightarrow 1$, the marginal benefit of higher taxes falls for each value of the tax rate. This leads to a reduction in the growth maximizing tax rate. When $\alpha+\beta=1$, the marginal benefit schedule intersects the marginal cost schedule at $\tau_{x k}^{g}=\frac{1-a}{a}$ : in this case, the marginal benefit is a horizontal line and equal to zero for all feasible values of the tax rate. Intuitively, when labor is endogenous, the tax rate maximizes the net return to capital as well as aggregate labor supply. Under exogenous labor supply, aggregate labor is invariant with respect to the tax rate. Hence, the growth maximizing tax rate is greater when labor-leisure is endogenous. This proves the existence of a unique growth maximizing 
tax rate.

\section{Insert Figure 1 Here}

\subsection{The Dynamics of Wealth Inequality}

We first consider the case where $\alpha+\beta<1$, and derive the transitional dynamics governing the law of motion of household capital holdings as in DG and Ghate (2005). We then characterize the equilibrium tax rate under majority voting. For any household, $h$, let $\eta_{h t}=\frac{K_{h t}}{K_{t}}, \eta_{h} \in[0,1]$, denote the relative capital holdings of the $h^{t h}$ household relative to the aggregate capital stock. ${ }^{13}$ The dynamic law of motion of household specific capital holdings is given by ${ }^{14}$

$$
\eta_{h t+1}=\eta_{h t}\left\{1+\frac{\xi\left(\tau_{k t}\right)\left[\frac{\frac{H_{h t}}{H_{h t}}}{\eta_{h t}}-1\right]}{\xi\left(\tau_{k t}\right)+\phi\left(\tau_{k t}\right)\left(1-\tau_{k t}\right)}\right\} .
$$

Equation (13) is the index of inequality in the model and governs the transitional dynamics of relative capital holdings of the $h^{\text {th }}$ household. It is easy to verify from equation (13) that the transition to the steady state is monotone and there is a unique stable steady state. This gives the following result.

Proposition 2 In the steady state, the factor holding ratios of agents converge to a mass point that is independent of the initial distribution of capital, i.e.,

$$
\frac{H_{h}}{H}=\eta_{h}=\frac{1}{N} \quad \forall h
$$

This holds for all feasible values of the tax rate.

\footnotetext{
${ }^{13}$ When $\eta_{h}=1$, then the $h^{\text {th }}$ household owns the entire capital stock.

${ }^{14}$ We divide equation (6) by equation (9) and simplify to get equation (13).
} 


\section{Proof. See Appendix}

The important implication of Proposition (2) is that the asymptotic dynamics of wealth inequality under leisure dependent utility is independent of the capital income tax rate. Incorporating leisure dependent utility does not change the unanimity results in DG and Ghate (2005). In the steady state every agent is a 'representative' agent and there is complete equality in relative factor holdings. Here the relative fraction of hours worked by households is also pinned by their relative capital holdings in the steady state. Each agent works the same fraction of hours in the steady state.

To obtain the equilibrium tax rate, after several manipulations, the household indirect utility function, $V_{h k t}$, can be written as follows:

$$
V_{h k t}=\mathrm{constant}+\log \left\{1+a N(\alpha+\beta) \frac{\left(1-\tau_{h k t}\right)}{\delta\left(\tau_{h k t}\right)} \eta_{h t}\right\}+(\alpha+\beta) \log \left(w_{t}\right) .
$$

The optimal tax rate, $\tau_{h k t}$, for the $h^{\text {th }}$ household is obtained from the household's first order condition with respect to (15), and is determined by the following first order condition, ${ }^{15}$

$\underbrace{\frac{(1-a)[(1-a)+a(1-\alpha-\beta)]}{a \tau_{h k t}}}_{M B}=\underbrace{\frac{a N(1-a) \eta_{h t}}{\left\{(1-a)+a\left[(1-\alpha-\beta)+(\alpha+\beta) N \eta_{h t}\right]\left(1-\tau_{h k t}\right)\right\}}+a(1-\alpha-\beta)}_{M C}$

\footnotetext{
${ }^{15}$ Technical details are available in the appendix. Throughout the paper, we assume that individual's care not only about how their optimal choices affect individual labor supply, but aggregate $H$ as well. It is sufficient to note that for any given values of $K_{t}$ and $K_{h t}$ the indirect utility function of single peaked with respect to $\tau_{k t}$. By the median voter theorem, this implies that the median household's preferred tax rate is the equilibrium tax rate in the economy. As is well known, this is a sufficient condition for the median voter theorem to hold.
} 
Two aspects deserve mention. First, from (16) it is easily verified that as $\eta_{h}$ (relative capital holdings) increase, the optimal tax rate of households, $\tau_{h k t}$, falls, as in DG and Ghate (2005). Intuitively, the right hand side of equation (16) corresponds to the marginal cost schedule of a rise in the tax rate facing households. The first term on the right hand side of equation (16) in increasing in $\eta_{h}$. Hence, a higher $\eta_{h}$ pushes the marginal cost up for each tax rate. This reduces the household's preferred tax rate. This is intuitive: the more capital rich households are, the more they care about their net capital income, and the less their preferred tax on capital. Second, equation (16) allows us to rank households in terms of their capital holdings and preferred tax rates. For capital-rich households (relative to the mean), $\eta_{h}>\frac{1}{N}$. This implies their preferred tax on capital will be less than a capital poor household whose capital holdings are less than the average, $\eta_{h}<\frac{1}{N}$. This is because the marginal cost for an increase in the tax rate is higher for the capital rich households. Hence, their preferred tax on capital is less compared to a capital poor household.

Using Proposition 2 we substitute $\eta_{h}=\frac{1}{N}$ into (16) to get the preferred tax rate of all households in the steady state:

$$
\underbrace{\frac{(1-a)[(1-a)+a(1-\alpha-\beta)]}{a \tau_{k h}}}_{M B}=\underbrace{\frac{a(1-a)}{\left(1-a \tau_{k h}\right)}+a(1-\alpha-\beta)}_{M C}, \quad h=\frac{1}{N} .
$$

The equilibrium tax is constant. Finally, setting $h=m$ in (17) yields the equilibrium tax rate under majority voting in the steady state, which is the preferred tax of the median voter. Let us denote this as $\tau_{m k}$. We compare $\tau_{m k}$ with $\tau_{e k}^{g}$, the latter 
determined by equation (10), which we re-write as,

$$
\underbrace{\frac{(1-a)[(1-a)+a(1-\alpha-\beta)]}{a \tau_{k}}}_{M B}=\underbrace{\frac{a(1-a)}{1-a \tau_{k}}+\frac{a^{2}(1-\alpha-\beta)\left(1-\tau_{k}\right)}{1-a \tau_{k}}}_{M C} .
$$

The left hand side of both (18) and (17) denote the marginal benefit schedule from higher taxes. These are identical. The difference lies in the marginal cost schedules. In particular, since $\frac{a(1-\tau)}{\left(1-a \tau_{k}\right)}<1$, for all $\tau_{k} \in[0,1]$. Hence, the marginal cost of a rise in the tax rate is greater for households in the steady state for each level of the tax rate. Thus, for higher values of the tax rate, the optimal tax of households in the steady state - as well as the median household's preferred tax rate - is less than the growth maximizing tax rate. This allows us to state our main result for this section:

Proposition 3 Let $\alpha+\beta<1$. While there is complete factor holding convergence in the steady state, the equilibrium capital income tax rate is strictly less than the growth maximizing tax rate: i.e., $\tau_{m k}<\tau_{e k}^{g}$.

Proposition (3) implies that factor holding convergence is not affected by voting over capital income taxes and incorporating leisure dependent utility. However, in direct contrast to DG and Ghate (2005), the equilibrium tax rate is lower than the growth maximizing tax rate. This happens for a specific reason. Since agents work less because they value leisure, they choose to tax themselves less, as depicted in equation (8). This leads to a lower equilibrium tax rate under majority voting and lower steady state growth. In DG and Ghate (2005), both tax rates are the same, while the inequality is reversed in AR: i.e., the tax rate chosen in a political equilibrium is greater than the growth maximizing tax rate. What is common to the current 
paper, DG, and Ghate (2005) is that initial inequality is not preserved under leisure dependent utility. ${ }^{16}$

\subsection{Dynamics of Wealth Inequality when $\alpha+\beta=1$.}

As in DG and Ghate (2005), the two tax rates coincide in the steady state when labor is exogenous. To see this, and following the same steps as before, the relative capital holdings of households (under exogenous labor) evolves according to

$$
\eta_{h t+1}=\eta_{h t}\left\{1+\frac{\xi\left(\tau_{k t}\right)\left[\frac{1}{\eta_{h t}}-1\right]}{\xi\left(\tau_{k t}\right)+\phi\left(\tau_{k t}\right)\left(1-\tau_{k t}\right)}\right\} .
$$

This implies that $\eta_{h t}=1, \forall h$ in the steady state. There is complete equality in the steady state. The indirect utility function of households is given by,

$$
V_{h t}=\mathrm{constant}+\log \left\{1+\frac{a}{1-a}\left(1-\tau_{k t}\right) H_{t} \eta_{h t}\right\}+(\alpha+\beta) \log \left(w_{t}\right) .
$$

Since agents take $H$ as given, the first order condition is given by

$$
\frac{\frac{a}{1-a} \eta_{h t} H_{t}}{1+\frac{a}{1-a} \eta_{h t} H_{t}\left(1-\tau_{k t}\right)}=(\alpha+\beta) \frac{1-a}{a} \tau_{k t} .
$$

Setting $\alpha+\beta=1$ implies that the optimal tax of the $h^{t h}$ household is given by,

$$
\tau_{h k t}=(1-a)\left\{1+\frac{1-a}{a \eta_{h t}}\right\} .
$$

The optimal tax rate is decreasing in the relative capital holdings of the $h^{\text {th }}$ household. Setting $h=m$ and $\eta_{m t}=1$ into this expression implies that $\tau_{m k x}=\frac{1-a}{a}$, which is the median household's preferred tax rate. Note that this is identical to the growth maximizing tax rate, $\tau_{x k}^{g}$, derived before.

\footnotetext{
${ }^{16}$ In contrast, in AR, factor holdings are constant and initial inequality is preserved in the steady state. Further, lower growth obtains for a different reason than in AR. Here unanimity holds and slower growth comes together with valued leisure. In AR, slower growth comes from conflicting choices over the tax rate, with a capital-poor median voter prevailing.
} 


\section{The Model with a Labor Income Tax}

The results in the previous section relied crucially on the household labor supply curve described by equation (8) in which labor supply is an increasing function of the tax rate. This leads to a lower equilibrium tax rate characterized by Proposition (3). The case of a linear capital income tax may not be realistic for many real world economies. ${ }^{17}$ We now extend the model and consider the dynamics of wealth inequality when voting occurs over a tax on labor income. ${ }^{18}$

The setup of the model is identical to the model where $G$ is financed by capital income taxation. The only difference is that we assume that the public infrastructure input, $G$, is financed by a specific tax, $\tau_{w t} \in[0,1]$, on labor income in each period. The government budget constraint is balanced in each period, and given by $G_{t}=\tau_{w t} w_{t} H_{t}$, where $w_{t}$ is the competitive wage rate. ${ }^{19}$

Households maximize (3) subject to (4) which yields the optimal consumption equation, $C_{h t}=\frac{\alpha}{\beta} K_{h t+1}$, the optimal capital accumulation equation, $K_{h t+1}=\frac{\beta}{\alpha+\beta}\left\{w_{t} H_{h t}(1-\right.$ $\left.\left.\tau_{w t}\right)+r_{t} K_{h t}\right\}$, and the agent's optimal labor supply equation,

$$
H_{h t}=(\alpha+\beta)-(1-\alpha-\beta) \frac{r_{t}}{w_{t}\left(1-\tau_{w t}\right)} .
$$

${ }^{17}$ This is true especially in Europe where there is a growing tendency to tax labor incomes more heavily than capital incomes. See Mendoza and Tesar (2003) and Quadrini (2005).

${ }^{18}$ The derivations of this section are detailed in Appendix B.

${ }^{19}$ Given (1), the rental rate to capital, $r_{t}$, and the wage rate, $w_{t}$, are given by, $r_{t}=\nu\left(\tau_{w t}\right) H_{t}^{\frac{1-a}{a}}$, where $\nu\left(\tau_{w t}\right)=a \tau_{w t}^{\frac{1-a}{a}}$ and, $w_{t}=\varphi\left(\tau_{w t}\right) H_{t}^{\frac{1-2 a}{a}} K_{t}$, where $\varphi\left(\tau_{w t}\right)=(1-a)^{\frac{1}{a}} \tau_{w t}^{\frac{1-a}{a}}$. The rental rate wage ratio is

$$
\frac{r_{t}}{w_{t}\left(1-\tau_{w t}\right)}=\frac{a H_{t}}{(1-a)^{\frac{1}{a}} K_{t}\left(1-\tau_{w t}\right)}
$$


Equation (24) is the optimal labor supply equation. Importantly, and opposite to the case of capital income taxation, household labor supply is decreasing in $\tau_{w t}$. This has an important implication for the steady state tax rate determined under majority voting. Aggregating the household capital accumulation equation above yields the aggregate capital accumulation equation:

$$
K_{t+1}=\frac{\beta}{\alpha+\beta}\left\{\varphi\left(\tau_{w t}\right)\left(1-\tau_{w t}\right)+\nu\left(\tau_{w t}\right)\right\} K_{t} H_{t}^{\frac{1-a}{a}}
$$

Similarly, aggregating across households in (24) yields the aggregate labor supply equation:

$$
H_{t}=\frac{N(\alpha+\beta)(1-a)^{\frac{1}{a}}\left(1-\tau_{w t}\right)}{(1-a)^{\frac{1}{a}}\left(1-\tau_{w t}\right)+(1-\alpha-\beta) a} .
$$

Aggregate labor supply, $H_{t}$, is also decreasing in the tax rate. ${ }^{20}$

The remaining analysis is similar to the case of voting over capital income taxes. The constant growth maximizing tax rate is obtained by solving for $\tau_{\text {ew }}^{g}$ from $\frac{\partial g_{t+1}}{\partial \tau_{w t}}=0$. From the first order condition: ${ }^{21}$,

$$
\frac{1-a}{a \tau_{e w}^{g}}=\frac{(1-a)^{\frac{1}{a}}}{(1-a)^{\frac{1}{a}}\left(1-\tau_{e w}^{g}\right)+a}+\frac{(1-a)(1-\alpha-\beta)}{\epsilon\left(\tau_{w}\right)\left(1-\tau_{e w}^{g}\right)}
$$

where $\tau_{\text {ew }}^{g} \in[0,1]$ denotes the growth maximizing tax rate under $\alpha+\beta<1$. It is easily verified from equation (28) that this equation defines a unique growth maximizing tax rate.

\footnotetext{
${ }^{20}$ Specifically, $H^{\prime}\left(\tau_{w t}\right)=-\frac{N(\alpha+\beta)(1-a)^{\frac{1}{a}}(1-\alpha-\beta) a}{(1-a)^{\frac{1}{a}}\left(1-\tau_{w t}\right)+(1-\alpha-\beta) a}<0 \quad \forall \tau_{w t}, 0<\tau_{w t}<1$.

${ }^{21}$ Substituting equation (24) into the household capital accumulation equation and aggregating across households yields: $\sum K_{h t+1}=K_{t+1}=\beta\left\{N w_{t}\left(1-\tau_{w t}\right)+r_{t} K_{t}\right\}$. Substituting out for the wage rate, $w$, the rental rate on capital $r$, and aggregate labor, $H$, and simplifying yields
}

$$
g_{t+1}=\text { constant } \cdot\left\{(1-a)^{\frac{1}{a}}\left(1-\tau_{w t}\right)+a\right\}\left(\tau_{w t} H_{t}\right)^{\frac{1-a}{a}} .
$$


The dynamics of wealth inequality are given by

$$
\eta_{h t+1}=\eta_{h t}\left\{1+\frac{\varphi\left(1-\tau_{w t}\right)\left[\frac{\frac{H_{h t}}{H_{t}}}{\eta_{h t}}-1\right]}{\varphi\left(1-\tau_{w t}\right)+\nu\left(\tau_{w t}\right)}\right\} .
$$

There is complete factor convergence in the steady state. ${ }^{22}$ This is consistent with the results derived when voting occurs over capital income taxation.

The equilibrium tax rate is obtained by substituting the individual decision rules of households back into their utility functions. After simplifying, we obtain, ${ }^{23}$

$$
W_{h t}=\text { constant }+\log \left\{1+\frac{a \eta_{h t} N(\alpha+\beta)(1-a)^{\frac{1}{a}}}{(1-a)^{\frac{1}{a}} \epsilon\left(\tau_{w t}\right)}\right\}+(\alpha+\beta) \log \left[w_{t}\left(1-\tau_{w t}\right)\right] .
$$

We show in Appendix B that the optimal tax rate for the $h^{\text {th }}$ household, $\tau_{h w t}$, is determined by the first order condition,

$\frac{\frac{a \eta_{h t} N(\alpha+\beta)(1-a)^{\frac{1}{a}}}{\epsilon\left(\tau_{h w t}\right)}}{(1-a)^{\frac{1}{a}}\left(1-\tau_{h w t}\right)+a\left[(1-\alpha-\beta)+\eta_{h t}(\alpha+\beta) N\right]}+(\alpha+\beta)\left[\frac{1-a}{a \tau_{h w t}}+\frac{1-2 a}{a} \cdot \frac{H^{\prime}}{H}\right]=(\alpha+\beta) \frac{1}{1-\tau_{h w t}}$.

Importantly, the optimal tax rate is decreasing in the relative capital holdings of the $h^{\text {th }}$ household. Since equation (29) implies factor holding convergence, setting $\eta_{h}=\frac{1}{N}$ in (31) yields a constant equilibrium tax rate for households in the steady state:

$$
\frac{1-a}{a} \frac{1}{\tau_{w}}=\frac{(1-a)^{\frac{1}{a}}\left(1-\tau_{w}\right)}{\epsilon\left(\tau_{w}\right)}\left\{\frac{(1-a)^{\frac{1}{a}}}{(1-a)^{\frac{1}{a}}\left(1-\tau_{w}\right)+a}\right\}+\frac{(1-a)(1-\alpha-\beta)}{\epsilon\left(\tau_{w}\right)\left(1-\tau_{w}\right)}
$$

We denote the constant steady state equilibrium tax rate, the preferred tax rate of the median voter, that solves (32) as $\tau_{m w}$. The left hand side of (32) corresponds to the marginal benefit of an increase in higher labor income taxes. The marginal

\footnotetext{
${ }^{22}$ Setting $\eta_{h t+1}=\eta_{h t}=\eta_{h}$ in (29) yields $\eta_{h}=\frac{H_{h}}{H}=\frac{1}{N}$.

${ }^{23}$ Define $\epsilon\left(\tau_{w t}\right)=(1-a)^{\frac{1}{a}}\left(1-\tau_{w t}\right)+(1-\alpha-\beta) a$
} 
benefit of an increase in taxes tends to infinity as $\tau_{w}$ tends to zero and converges to $\frac{1-a}{a}$ as $\tau_{w}$ tends to $1 .{ }^{24}$ Hence, the marginal benefit curve is declining in the tax rate. The right hand side of equation (32) corresponds to the marginal cost (MC) of an increase in higher labor income taxes. Since the marginal cost curve at $\tau_{w}=0$ is greater than zero, and the marginal cost curve at $\tau_{w}=1$ approaches infinity, there exists a unique equilibrium tax rate.

A comparison of equations (32) and (28) determines the main result. We summarize this in terms of the following proposition.

Proposition 4 Let $\alpha+\beta<1$. While there is complete factor holding convergence in the steady state, the equilibrium labor income tax rate is greater than the growth maximizing tax rate: i.e., $\tau_{w m}>\tau_{e w}^{g}$.

Proof. The proof involves a simple comparison of the marginal cost schedules of (32) and (28) since the marginal benefit schedules are identical. Since $\frac{(1-a)^{\frac{1}{a}}\left(1-\tau_{w}\right)}{\epsilon\left(\tau_{w}\right)}<$ $1, \forall \tau_{w} \in[0,1]$, the marginal cost curve - for a rise in each tax rate - is lower than the marginal cost schedule for the growth maximizing tax rate. Hence, the equilibrium tax rate under majority voting exceeds the growth maximizing tax rate in the steady state.

Intuitively, and in contrast to the case of capital income taxation, since households value leisure, they work less, but choose to tax themselves more than the growth maximizing policy. This follows from equations (24) and (26). This leads to lower

\footnotetext{
${ }^{24}$ The derivative of the marginal benefit schedule with respect to $\tau_{w}$ is: $-\frac{1-a}{a} \frac{1}{\tau_{w}^{2}}<0, \quad \forall \tau_{w} \in[0,1]$
} 
Voting, Wealth Heterogeneity, and Endogenous Labor Supply 21

steady state growth, even though there is complete factor holding convergence in the steady state.

\subsection{Dynamics of Wealth Inequality when $\alpha+\beta=1$}

When the labor-leisure choice is exogenous $(\alpha+\beta=1)$, the steady tax rate coincides with the growth maximizing tax rate. To see this, set $\alpha+\beta=1$ in (32) and (28). The marginal benefit and marginal cost schedules are identical, and given by,

$$
\frac{1-a}{a \tau_{w}}=\frac{(1-a)^{\frac{1}{a}}}{(1-a)^{\frac{1}{a}}\left(1-\tau_{w}\right)+a},
$$

which yields a closed form solution for the constant growth maximizing tax rate:

$$
\tau_{w}^{g}=\frac{\left[(1-a)^{\frac{1}{a}}+a\right]}{(1-a)^{\frac{1-a}{a}}} .
$$

In the steady state, the equilibrium tax rate under majority voting equals the growth maximizing tax rate.

\section{The Model with A General Income Tax}

We now consider the case of a general flat income tax $\left(\tau_{k}=\tau_{w}=\tau_{y}\right)$. We assume that the public infrastructure input, $G$, is financed by a constant general income tax, $\tau_{y} \in[0,1]$ as in Barro (1990) and Ghate (2005). ${ }^{25}$ The government budget constraint is balanced in each period, and given by

$$
G_{t}=\tau_{y t} Y_{t} .
$$

\footnotetext{
${ }^{25}$ In Ghate (2005), the labor leisure choice is exogenous. Here it is endogenous
} 
The setup of the rest of the model follows Ghate (2005) and the two cases considered above. $^{26}$ It is easily shown that the preferred constant steady state tax rate for each household is given by, ${ }^{27}$

$$
\tau_{h y}=1-a, \forall h
$$

This is also the median households preferred tax rate. Likewise, the constant growth maximizing tax rate is given by: $\tau_{y}^{g}=1-a .{ }^{28}$ There is AK growth in the steady state. This generalizes the results of Ghate (2005) to the case of endogenous labor supply. This also extends the well known Barro (1990) result that a growth maximizing policy is always welfare maximizing with identical individuals. In the current framework, because the marginal costs and benefits of higher taxes are exactly proportional (unlike the case of capital and labor income taxation), every household's preferred tax rate coincides with the growth maximizing policy even though agents value leisure.

\section{Conclusion}

To summarize, the contribution that this paper makes is to examine the implications of an endogenous labor leisure choice and factor income taxation on the political and

\footnotetext{
${ }^{26}$ The factor rewards are computed in the standard way and are given by, $r_{t}=\tau_{y t}^{\frac{1-a}{a}} H^{\frac{1-a}{a}}$, and,
} $w_{t}=\frac{1-a}{a} K_{t} \tau_{y t}^{\frac{1-a}{a}} H^{\frac{1-2 a}{a}}$, where $r$ denotes the competitive return to capital, while $w$ denotes the return to labor. Both $r$ and $w$ are increasing in the tax rate, with the rental - wage ratio given by $\frac{r_{t}}{w_{t}}=\frac{a H_{t}}{(1-a) K_{t}}$. Note that the rental wage ratio here is identical to (2) and is independent of $\tau_{y t}$.

${ }^{27}$ The indirect utility function, $W_{h t}^{y}$, is given by: $W_{h t}^{y}=$ constant $+\log \left[1+\frac{a}{1-a} \frac{H_{t}}{K_{t}} K_{h t}\right]+(\alpha+$ $\beta) \log \left[w_{t}\left(1-\tau_{\text {hyt }}\right)\right]$.

${ }^{28}$ The equation for the gross growth factor is given by

$$
g_{t+1}=\frac{K_{t+1}}{K_{t}}=\frac{\beta}{\alpha+\beta} \frac{1}{a}\left(1-\tau_{y t}\right) \tau_{y t}^{\frac{1-a}{a}} H_{t}^{\frac{1-a}{a}},
$$


Voting, Wealth Heterogeneity, and Endogenous Labor Supply 23

economic equilibrium in a heterogenous agent Barro (1990) type endogenous growth framework. We allow for voting over a tax on capital income, labor income, and a general income tax, with voting occuring over a single issue.

This paper makes two contributions. We show that complete factor holding convergence occurs in the steady state. Hence, wealth dynamics are independent of the underlying factor-specific tax system in the steady state. These results are consistent with DG and Ghate (2005). While there is convergence in factor holdings, we show that the equilibrium tax rate diverges from the growth maximizing tax rate when voting occurs over capital and labor income taxes, but only coincides with the growth maximizing tax rate when household vote over a general income tax. Importantly, the divergence between the equilibrium tax rate and the growth maximizing tax rate depends crucially on how labor supply responds to capital income taxation, labor income taxation, and a general income tax.

Future work could allow for infrastructure funded by a non-linear progressive tax system, with voting occuring over the progressivity parameter. Also, in the current framework, the initial distribution of wealth does not matter for steady state convergence. This is typical of the OLG setup used in this paper. One possible extension would be to allow for initial inequality to affect the transition path, with an initially more unequal economy taking longer to reach the steady state. Finally, we choose the current setup to keep the inter-temporal wealth distribution tractable. Alternatively, we could allow agents to care about the utility of their children, as opposed to the level of capital that they bequeath. We leave this for future research. 
Voting, Wealth Heterogeneity, and Endogenous Labor Supply 24

\section{A Appendix}

Proof. Proposition (1). Log-differentiating (10) with respect to $\tau_{k t}$, and re-arranging, yields the following first order condition:

$$
\frac{a}{(1-a)+a\left(1-\tau_{k t}\right)}=\frac{1-a}{a \tau_{k t}}+\frac{(1-a)(1-\alpha-\beta)}{\delta\left(\tau_{k t}\right)} .
$$

Multiplying through both terms in (38) by $\delta\left(\tau_{k t}\right)$ and simplifying implies

$$
\underbrace{\frac{a \delta\left(\tau_{k t}\right)}{\left(1-a \tau_{k t}\right)}}_{M C}=\underbrace{\frac{(1-a)[(1-a)+a(1-\alpha-\beta)]}{a \tau_{k t}}}_{M B} .
$$

Substituting for $\delta\left(\tau_{k t}\right)=(1-a)+a(1-\alpha-\beta)\left(1-\tau_{k t}\right)$ above, this can be simplified to

$$
\underbrace{(1-a)\left\{a \tau_{k}-(1-a)\right\}}_{M C}=\underbrace{(1-\alpha-\beta) a\left[(1-a)\left(1-a \tau_{k}\right)-a(1-\tau) a \tau_{k}\right]}_{M B},
$$

since equation (40) defines a constant tax rate, $\tau_{k}$. Notice that changes in $\alpha$ and $\beta$ only lead to changes in the marginal benefit schedule. Let $\alpha+\beta<1$. To obtain Figure 1 , evaluating the left hand side of (40) when $\tau_{k}=\{0,1\}$ implies $L H S(0)=-(1-a)^{2}$ and LHS $(1)=(2 a-1)(1-a)$, with the marginal cost schedule increasing linearly in $\tau$ and intersecting the x-axis at $\tau_{k}=\frac{1-a}{a}$. Evaluating the right hand side of (40) when $\tau_{k}=$ $\{0,1\}$ implies $R H S(0)=(1-\alpha-\beta) a(1-a)$ and $R H S(1)=(1-\alpha-\beta) a(1-a)^{2}$, with the marginal benefit schedule decreasing in $\tau_{k}, \forall \tau_{k} \in[0,1]$. The existence of a growth maximizing tax rate occurs when, $\operatorname{LHS}(1)>R H S(1)$, or $2 a-1>(1-\alpha-\beta) a(1-a)$. Notice that when $\tau_{k}=\frac{1-a}{a}$, the marginal benefit term is positive. Hence, $\tau_{k}=\frac{1-a}{a}$ cannot be the growth maximizing tax rate. Since, the marginal benefit is falling, when $\alpha+\beta<1, \tau_{e k}^{g}>\tau_{x k}^{g}$. Note that in the current setup multiple equilibria will 
not arise. This is because the marginal benefit schedule is monotonically decreasing in the tax rate on capital income, while the marginal cost schedule is monotonically increasing in the tax rate. The condition in Proposition (1) under, $\alpha+\beta<1$, simply ensures that an equilibrium exists.

Proof. Proposition (2). Setting $\eta_{h t+1}=\eta_{h t}=\eta_{h}$ in (13) implies that

$$
\frac{H_{h t}}{H_{t}}=\eta_{h} \quad \forall h .
$$

Dividing equation (7) by the expression for $H_{t}$ in (8) and simplifying yields,

$$
\frac{H_{h t}}{H_{t}}=\frac{\delta\left(\tau_{k t}\right)}{N(1-a)}-\frac{a(1-\alpha-\beta)}{(1-a)} \frac{K_{h t}}{K_{t}}\left(1-\tau_{k t}\right) .
$$

Since equation (13) implies that

$$
\frac{\frac{H_{h t}}{H_{t}}}{\eta_{h t}}=1
$$

in the steady state, dividing both sides of (42) by $\frac{K_{h t}}{K_{t}}$, setting $\frac{\frac{H_{h t}}{H_{t}}}{\eta_{h t}}=1$, and simplifying yields the result.

Next, we derive the first order condition of the $h^{\text {th }}$ household in equation (16). The $h^{\text {th }}$ agent's indirect utility function is given by,

$$
V_{h k t}=\text { constant }+\underbrace{\log \left\{1+a N(\alpha+\beta) \frac{\left(1-\tau_{h k t}\right)}{\delta\left(\tau_{h k t}\right)} \eta_{h k t}\right\}}_{\text {TermI }}+\underbrace{(\alpha+\beta) \log \left(w_{t}\right)}_{\text {TermII }} .
$$

Evaluating the first term $(I)$ and simplifying yields

$$
\frac{\partial T e r m I}{\partial \tau_{h k t}}=\frac{-a N(\alpha+\beta)(1-a) \eta_{h t}}{\left\{a\left[(1-\alpha-\beta)+(\alpha+\beta) N \eta_{h t}\right]\left(1-\tau_{h k t}\right)\right\}} \frac{1}{\delta\left(\tau_{h k t}\right)} .
$$

Evaluating the first term $(I I)$ and simplifying yields

$$
\frac{\partial T e r m I I}{\partial \tau_{h k t}}=\frac{\xi^{\prime}\left(\tau_{h k t}\right)}{\xi\left(\tau_{h k t}\right)}+\frac{(1-2 a)}{a} \frac{H^{\prime}\left(\tau_{h k t}\right)}{H\left(\tau_{h k t}\right)} .
$$


Note that $\frac{\xi^{\prime}\left(\tau_{h k t}\right)}{\xi\left(\tau_{h k t}\right)}=\frac{(1-a)}{a \tau_{h k t}}$, while $\frac{H^{\prime}\left(\tau_{h k t}\right)}{H\left(\tau_{h k t}\right)}=\frac{a(1-\alpha-\beta)}{\delta\left(\tau_{h k t}\right)}$. Substituting these expressions back and re-arranging terms yields (16).

\section{B Dynamics of Wealth Inequality under a Labor Income Tax}

To obtain equation (29), we substitute out the factor prices from the household capital accumulation equation. This yields,

$$
K_{h t+1}=\frac{\beta}{\alpha+\beta}\left\{\frac{\varphi\left(\tau_{w t}\right) H_{t}^{\frac{1-2 a}{a}}\left(1-\tau_{w t}\right) H_{h t}}{\eta_{h t}}+\nu\left(\tau_{h w t}\right) H_{t}^{\frac{1-a}{a}}\right\} .
$$

Dividing the above expression by equation(25) and simplifying yields equation (29) from which if follows that, $\eta_{h}=\frac{H_{h}}{H}=\frac{1}{N}$. To obtain (30), substitute out the expression for $C_{h t}$ in (3) with the optimal consumption equation, and equation (24) noting that from $(24), 1-H_{h t}=\frac{K_{h t+1}(1-\alpha-\beta)}{\beta w_{t}\left(1-\tau_{w t}\right)}$. The indirect utility function is then given by,

$$
W_{h t}=\text { constant }+\log K_{h t+1}-(1-\alpha-\beta) w_{t}-(1-\alpha-\beta) \log \left(1-\tau_{h w t}\right) .
$$

Substitute out, $\frac{K_{h t+1}(1-\alpha-\beta)}{\beta w_{t}\left(1-\tau_{w t}\right)}=\frac{\beta}{\alpha+\beta}\left\{H_{h t}+\frac{r_{t}}{w_{t}\left(1-\tau_{w t}\right)} K_{h t}\right\}$, in the above expression for $W_{h t}$, and then noting that from (23) and (24) that,

$$
H_{h t}+\frac{a}{(1-a)^{\frac{1}{a}}} \frac{H_{t}}{K_{t}\left(1-\tau_{w t}\right)}=\frac{(\alpha+\beta) a H_{t} K_{h t}}{(1-a)^{\frac{1}{a}} K_{t}\left(1-\tau_{w t}\right)},
$$

the indirect utility function of agents, given by equation (30) obtains:

$$
W_{h t}=\text { constant }+\underbrace{\log \left\{1+\frac{a \eta_{h t} N(\alpha+\beta)(1-a)^{\frac{1}{a}}}{(1-a)^{\frac{1}{a}} \epsilon\left(\tau_{h w t}\right)}\right\}}_{\text {TermI }}+\underbrace{(\alpha+\beta) \log \left[w_{t}\left(1-\tau_{h w t}\right)\right]}_{\text {TermII }} .
$$


We now derive (32). ${ }^{29}$ Differentiating the first term $(I)$ with respect to $\tau_{h w t}$ and simplifying yields

$$
\frac{\partial \operatorname{TermI}}{\partial \tau_{h w t}}=\frac{\frac{a \eta_{h t} N(\alpha+\beta)(1-a)^{\frac{1}{a}}}{\epsilon\left(\tau_{h w t}\right)}}{\epsilon\left(\tau_{h w t}\right)+a \eta_{h t} N(\alpha+\beta)} .
$$

Differentiating the second term $(I I)$ and simplifying yields,

$$
\frac{\partial T e r m I I}{\partial \tau_{h w t}}=(\alpha+\beta)\left[\frac{\varphi^{\prime}\left(\tau_{h w t}\right)}{\varphi\left(\tau_{h w t}\right)}+\frac{(1-2 a)}{a} \frac{H^{\prime}\left(\tau_{h w t}\right)}{H\left(\tau_{h w t}\right)}-\frac{1}{1-\tau_{h w t}}\right] .
$$

Combining both equations (49) and (50), setting the resulting expression equal to zero, and simplifying yields equation (31). Finally, note that $\frac{\varphi^{\prime}\left(\tau_{h w t}\right)}{\varphi\left(\tau_{h w t}\right)}=\frac{1-a}{a \tau_{h w t}}$, and $\frac{H^{\prime}\left(\tau_{h w t}\right)}{H\left(\tau_{\text {hwt }}\right)}=-\frac{(1-\alpha-\beta) a}{\epsilon\left(\tau_{\text {hwt }}\right)\left(1-\tau_{h w t}\right)}$. Substituting these expressions as well the steady state equilibrium factor holdings $\left(\eta_{h}=\frac{1}{N}\right)$ into (31) yields the optimal tax rate for households in the steady state, determined by equation (32).

\footnotetext{
${ }^{29}$ It can be verified that single - peakedness holds, and therefore the first order condition of the indirect utility function with respect to the tax rate is sufficient to the determine the optimal tax rate under a majority rule equilibrium (setting $h=m$ ). Technical details are available from the author on request.
} 
Voting, Wealth Heterogeneity, and Endogenous Labor Supply 28

\section{References}

Aghion, P., and Bolton, P. (1997), A Theory of Trickle-Down Growth and Development, Review of Economic Studies 64, 151-172.

Alesina, A., and Rodrik, D. (1994), Distributive Conflict and Economic Growth, Quarterly Journal of Economics 109, 465-490.

Barro, R.J. (1990), Government Spending in a Simple Model of Endogenous Growth, Journal of Political Economy 98, 103-25.

Barro, R. J., and Sala-i-Martin, X. (1995) Economic Growth, MIT Press, Cambridge, Mass.

Bertola, G. (1993), Factor Shares and Savings in Endogenous Growth, American Economic Review 83, 1185 - 1198.

Bond, S., Leblebicioglu, A., and Schianterlli, F. (2004), Capital Accumulation and Growth: A New Look at the Empirical Evidence, Boston College Department of Economics Working Paper No. 591, Boston College.

Das, S., and Ghate, C. (2004), Endogenous Distribution, Politics, and the GrowthEquity Tradeoff, Contribution to Macroeconomics 4(1), Article 6, Berkeley Electronic Press.

de Hek, P. (1998), An Aggregative Model of Capital Accumulation with Leisure Dependent Utility, Journal of Economic Dynamics and Control 23, 255-276.

de Hek, P. (2006), On taxation in a two-sector endogenous growth model with endogenous labor supply, Journal of Economic Dynamics and Control 30, 655-685.

Eriksson, C. (1996), Economic Growth with Endogenous Labor Supply, European 
Voting, Wealth Heterogeneity, and Endogenous Labor Supply 29

Journal of Political Economy 12, 533-544.

Ghate, C. (2005), Endogenous Distribution and Equilibrium Growth: A Note, Bulletin of Economic Research, 57, 171-183.

Ladron-de-Guevara, A., Ortigueira, S., and Santos, M. (1997), A Two Sector Model of Endogenous Growth with Leisure, Review of Economic Studies 66, 609 - 631.

Ladron-de-Guevara, A., Ortigueira, S., and Santos, M. (1999), Equilibrium Dynamics in Two Sector Models of Endogenous Growth, Journal of Economic Dynamics and Control 21, 115-143.

Li, D. (2002), Is the AK Model Still Alive? The long run relation between growth and investment re-examined, Canadian Journal of Economics 35, 93-114

Mendoza, E., and Tesar, L. (2003), A Quantitative Analysis of Tax Competition v. Tax Coordination under Perfect Capital Mobility, NBER Working Paper Series No. 9746.

Ortigueira, S. (1998), Fiscal Policy in an Endogenous Growth Model with Human Capital Accumulation, Journal of Monetary Economics 21, 309-341.

Ortigueira, S. (2000), A Dynamic Analysis of an Endogenous Growth Model with Leisure, Economic Theory 16, 43-62.

Quadrini, V. (2005), Policy Commitment and the Welfare Gains from Capital Market Liberalization, European Economic Review 49, 1927 - 1951.

Rebelo, S. (1991), Long Run Policy Analysis and Long Run Growth, Journal of Political Economy 99, 500-521.

Stiglitz, J. (1969), Distribution of Income and Wealth Among Individuals, Econometrica 37, 382-397. 
Voting, Wealth Heterogeneity, and Endogenous Labor Supply 30

Turnovsky, S. (1999), Fiscal Policy and Growth in a Small Open Economy, Canadian Journal of Economics 32, 1191-1214.

Turnovsky, S. (2000), Fiscal Policy, Elastic Labor Supply, and Endogenous Growth, Journal of Monetary Economics 45, 185-210.

Corresponding Author: Chetan Ghate, Assistant Professor, Planning Unit, Indian Statistical Institute - Delhi Center, 7 S.J.S. Sansanwal Marg, New Delhi - 110016, India. Tel: 91-11-4149-3938. Fax: 91-11-4149-3981. Email: cghate@isid.ac.in 


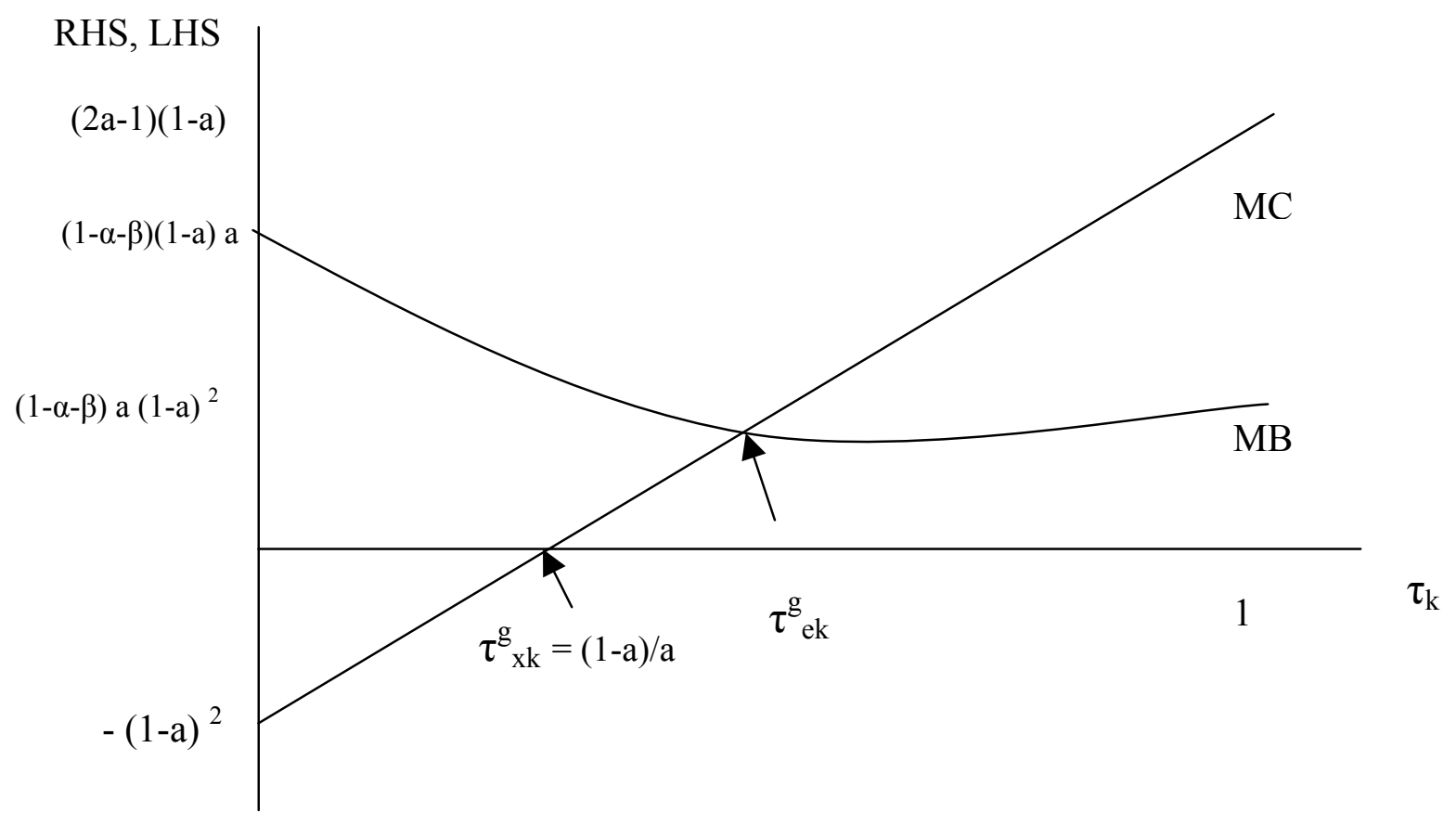

FIGURE 1: The Growth Maximizing Tax Rate 